\title{
On Libertarianism as an Explanatory Hypothesis
}

\author{
Andrew Kissel \\ Old Dominion University \\ Department of Philosophy and Religious Studies \\ 9011 Batten Arts \& Letters \\ Norfolk, VA 23529 \\ akissel@,odu.edu
}

\section{NOTE: THIS IS THE AUTHOR'S POST-PRINT MANUSCRIPT!!! PLEASE DO NOT CITE THIS VERSION WITHOUT PERMISSION OF THE AUTHOR.}

To appear in: Southwest Philosophy Review, 2019, Volume 35, Issue 2, pages 91-110.

https://www.pdcnet.org/swphilreview/content/swphilreview_201900350002 00910110

\begin{abstract}
:
Recently, several libertarian philosophers have argued that we appear free on the basis of widespread experience, and that this appearance justifies believing that we enjoy libertarian free will (e.g. Pink 2004 and Swinburne 2013). Such arguments have a long history in philosophy but have been easily dismissed on one of two grounds: either the appearance of freedom does not exist, or else it is an illusion. In this paper, I argue that although presentations of the argument have been historically inadequate, non-libertarians have also seriously underappreciated the force of libertarian appeals to phenomenology. I show that, when properly construed, the appearance of freedom constitutes a wide range of diverse phenomena in need of explanation, of which extant non-libertarian alternatives provide only partial explanations, or else fail to explain altogether. In identifying this lacuna, I take the first step towards providing a better nonlibertarian alternative.
\end{abstract}

In the context of debates about free will, the oft-quoted Samuel Johnson observed, 'All theory is against the freedom of will; all experience for it.' (Boswell, 1993, 291). For many people, it just seems obvious that we appear to be free. Furthermore, numerous philosophers have been quick to observe that there seems to be a widespread conviction in favor of libertarian freedom, free will that is incompatible with causal determinism, over non-libertarian (including compatibilist, hard determinist, and hard incompatibilist) alternatives. In recent years, such 
anecdotal evidence has been supplemented by a flurry of empirical work devoted to the study of folk attitudes towards free will. ${ }^{1}$ These studies seek to determine whether there really is a widespread conviction that free will exists, and if so, where these convictions might come from.

In conjunction with this recent empirical work, contemporary philosophers have attempted to revive what I call psychological arguments for free will. ${ }^{2}$ Broadly, psychological arguments are united under the idea that widespread convictions of the form, "It appears to me that I am free," on some understanding of 'appears,' justify thinking that we are probably free. ${ }^{3}$ For example, Timothy O'Connor argues that we appear free in the sense that we experience our own voluntary activities as not necessitated by prior causes, and this experience justifies accepting his preferred flavor of free will, since he thinks we usually get things right about our own experience $(1995,106)$. Put simply: we appear free, so we probably are free.

Unfortunately, details about the particular appearance of freedom, and the justificatory status of that appearance, are often obscured in historical presentations of psychological arguments. As a result, the response from non-libertarians has largely fallen into two categories: they either deny the appearance of freedom, or they point out that the appearance of freedom could be an illusion. ${ }^{4}$ In either case, meaningful discussion of the apparently widespread appearance of freedom threatens to fall by the wayside. This is a shame. The free will problem has remained prominent for millenia in large part because it focuses on something with which everyone has intimate, personal acquaintance: their experience of their own choices.

\footnotetext{
${ }^{1}$ See Nahmias et. al. (2004); Nichols \& Knobe (2007); Deery (2013) and (2015); Sarkissian (2011)

${ }^{2}$ See Campbell (1967); O’Connor (1995, 106); Pink (2004, 122); Searle (2007); Mawson (2011); Swinburne (2013, 201)

${ }^{3}$ For historical examples, see Reid (1788) and Descartes (CSMK, 342)

${ }^{4}$ Hobbes (1656/2005); Spinoza (1677/2005); Magill (1997); Smilansky (2005); Sommers (2007); Nichols (2015).

For a recent exception, see Horgan (2011a)
} 
The purpose of the present paper is to redirect discussions surrounding the appearance of freedom in a more fruitful direction by presenting and clarifying a version of the psychological argument for free will that addresses the historical responses. In particular, I argue that the appearance of freedom constitutes a range of data in need of explanation. As it currently stands, libertarianism provides the best extant explanation of that data, ceteris paribus, and so is preferable on the basis of an inference to the best explanation (IBE). ${ }^{5}$ By contrast, nonlibertarians have provided only partial explanations, or have failed to account for the data altogether. As a result, I argue that non-libertarians have seriously underappreciated the force of libertarian appeals to the appearance of freedom. The ultimate goal of the paper is not necessarily to vindicate libertarianism, but to draw attention to a lacuna in non-libertarian responses to psychological arguments for free will based on the phenomenology of freedom.

\section{Learning from Past Failures}

After trying unsuccessfully to persuade Pierre Gassendi of his views on free will, Descartes responds, "I affirm what I have experienced and what anyone else can experience for himself, whereas your denial seems merely to be based on your own apparent failure to have the appropriate experience..." Descartes assumed all people could enjoy the appearances of freedom of the will via introspective experience. And given Descartes' view that whatever is seen clearly and distinctly is true, he argued it must be the case that we actually are free. ${ }^{7}$

\footnotetext{
${ }^{5}$ As I will clarify later in the paper, the ceteris paribus clause here assumes that libertarianism is a coherent theory that is not inconsistent with our best science, e.g. that it can be presented in a suitably naturalistic form.

${ }^{6}$ (CSM II, 260)

7 "I now seem to be able to lay it down as a general rule that whatever I perceive very clearly and distinctly is true." (CSM II, 24) I use Descartes' argument here as a model of psychological arguments for free will more generally. Although my focus is on libertarian arguments, I do not mean to imply that Descartes is a libertarian in the contemporary sense.
} 
The stand-off between Descartes and Gassendi regarding the appearance of freedom is part of a larger pattern for psychological arguments for free will. One philosopher points to an experience they have had, the other philosopher denies ever having had the experience. Such stand-offs are exacerbated by the fact that philosophers have failed to settle on a univocal description of the putative experience that constitutes the appearance of freedom. ${ }^{8}$ As such, it has been easy to dismiss psychological arguments for free will.

If the appearance of freedom is to support believing in free will, then the first step is to get clearer on what experiences support that appearance. Generally speaking, the experiences in question revolve around the exercise of agency, and quite often involve cases of choice. They are often taken to be commonsensical, in that everyone has had them, and are easily illustrated by one key example. Nevertheless, the variety of descriptions found in the literature and upon personal reflection suggests that there really is no canonical or univocal 'appearance of freedom'. Consider the following (abbreviated) list:

- The experience of agency- It appears that I am active with respect to my actions (Swinburne, 2013, 201; Moore, 2016; Horgan 2011a, 78).

- The experience of self-as-source- It appears that my choices result from me, as opposed to resulting from mental states that I have (Horgan, 2011a, 79).

- The experience of being an uncaused cause- It appears that I cause my actions, but nothing causes me to act as I do (Mawson, 2011, 151; Swinburne 2013, 201).

- The experience of exercising the power of control- It appears that I exert an effort to guide and control my choices (Pink, 2010; Campbell, 1967, 57).

\footnotetext{
${ }^{8}$ In fact, they often seem to invoke beliefs, rather than experiences. For present purposes, I focus on experiences of freedom, rather than beliefs regarding freedom. For more on the latter, see Kissel (2018).
} 
- The experience of a psychological causal gap- There appears to be a gap in the psychological chain of causation at the point of choice (Searle, 2003, 269).

- The experience of indeterminism- It appears that choice is made via an indeterministic, rather than a deterministic, process (Searle, 2007, 74-75).

- The experience of not being necessitated by one's reasons- It appears that the causes leading up to my choice do not causally necessitate the choice (Swinburne, 2013, 202; O’Connor, 1995, 200; Descartes CSM II, 260).

- The experience of choosing in view of one's reasons- It appears that the consideration and weighing of reasons influences choice in a non-deterministic way (Swinburne, 2013, 202; O’Connor 1995, 200).

- The experience of being able to choose otherwise in an unconditional sense- It appears that I could have made a different choice than I did, even if all facts about me and the world leading up to my choice were the same (O'Connor, 1995, 200).

- The experience of openness- It appears that, prior to choosing, there are numerous courses of action available (Horgan, Tienson, \& Graham, 2003, 323; Sripada, 2016, 2929-2930).

Although there are almost certainly deep conceptual connections between the items on the above list, each description describes a unique experience with its own purported content. It seems, then, that when discussing the 'appearance of freedom', we are actually discussing a patchwork umbrella term that applies to a collection of heterogeneous experiences, not a term that picks out one univocal experience.

This is an important lesson when considering whether appearances support believing in free will. While it may be true that Pierre Gassendi never had an experience of free will, full 
stop, it seems much less likely that he never had any of the experiences on the above list. When taken as a collective whole, the traditional response of baldly denying the appearance of freedom is revealed to be inadequate. I do not mean to argue here that every description of the appearances of freedom must be accepted. To be sure, haggling about the legitimacy of any particular experience is to be expected, with certain experiences added, dropped, or refined as the dialogue progresses. Rather, my point here is that the full scope of the appearances of freedom cannot be easily dismissed when presented in adequate detail.

Once the full range of appearances is acknowledged, a further question remains. Why should the fact that we appear free provide any reason to think we actually are free? After all, the appearances could be an illusion. In one of the earliest examples of this objection, Hobbes argues that a spinning top would think it was free if it experienced its motions but did not experience what had set it spinning. ${ }^{9}$ Men who experience free will could be similarly mistaken about their own abilities, and so the appearances of freedom cannot justify believing in free will.

Responses to the charge of illusion from libertarians has been historically inadequate. Descartes relied on his doctrine of clear and distinct ideas. ${ }^{10}$ More recently, philosophers like Richard Swinburne have relied on epistemic conservatism. Briefly, epistemic conservatism holds that, "If it seems to me that $p$, then probably $p$, absent defeaters." 11 These epistemic principles are contentious in themselves. But even if they are accepted, the possibility that the appearances could be mistaken remains. If intelligent peers think the appearances are illusions, then the defeater clause is triggered, and the appearances lose all of their justificatory force.

\footnotetext{
${ }^{9}$ Hobbes $(1656 / 2005,41)$

10 "I now seem to be able to lay it down as a general rule that whatever I perceive very clearly and distinctly is true." (CSM II, 24)

${ }^{11}$ Compare Richard Swinburne's Principle of Credulity, “[A]ny basic belief... is probably true... on the believer's evidence that he believes it” $(2013,201)$ See also O'Connor $(1995,106)$.
} 
On my view, the appearances of freedom constitute a body of data in need of explaining. They justify believing in a particular theory of free will only to the extent that the theory in question can explain the data. In which case, the data supports believing in libertarianism if it can be shown that libertarianism provides the best explanation of the widest range of that data.

By recasting the psychological argument for free will as an inference to the best explanation (IBE), the point that appearances could be illusions becomes an alternative explanation of the phenomena. In which case, pointing out that appearances of freedom could be an illusion does nothing to undermine the justificatory status of the appearances of freedom. Rather, we must evaluate which theory provides the better explanation of the experiences canvassed above: some form of libertarianism or some form of non-libertarianism?

Previous versions of the psychological argument for free will were practically nonstarters. Opponents denied the appearance of freedom, or else pointed out that the appearance could be mistaken. I have argued here that these objections are not yet decisive by pointing out the wide diversity of the appearances of freedom and placing them in the context of an IBE. In the next section, I will argue that, as it currently stands, libertarianism has a more fully worked out explanation of the widest set of appearances, and so is the best explanation currently on offer. However, a few points are in order before I take up that project in earnest.

First, the wide variety of appearances to be explained can become a problem for developing the libertarian IBE if libertarians and non-libertarians are not seeking to explain the same phenomena. ${ }^{12}$ For example, if one theory explains the appearance that my reasons do not causally necessitate my choice, and nothing else, while an alternative theory explains the appearance that my act of choosing is an uncaused cause, and nothing else, there is no ground for

\footnotetext{
${ }^{12}$ See Nahmias et. al., (2004) for possible differences between libertarian and non-libertarian descriptions of appearances of freedom.
} 
comparing these theories via an IBE. They lack a common ground. For this reason, there must be some agreement between libertarians and non-libertarians about which appearances are in need of explaining. The theory that wins out provides, other things being equal, an explanation of the largest set of appearances of freedom.

This discussion suggests a condition of adequacy on the libertarian IBE. If we are to compare libertarian and non-libertarian explanations of the appearances of freedom, then we need agreed upon phenomena in need of explanation. Call this the Agreement Condition. Furthermore, other things being equal, the theory of free will that explains the widest set of appearances is the better explanation. It is worth flagging at this point that not all libertarian theories will be on equal footing with respect to explaining a wide array of appearances of freedom. I will return to this point later in the paper.

Second, if the experiences canvassed above are to be successfully embedded in a libertarian IBE, we must treat them as phenomenological claims. ${ }^{13}$ Appearance claims in the phenomenological sense are not easy to characterize, in large measure because they concern the most vexed of philosophical issues: consciousness. Nevertheless, I hope that the following is, for present purposes, uncontentious. When I say in the phenomenological sense, "It appears to me that there is a tree in front of me," I am describing representational properties of my experience, as in response to the question, "What are you experiencing?" Appearance claims in this sense describe representational properties of experiential states- what are sometimes called

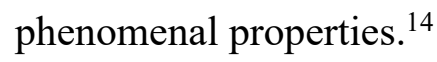

\footnotetext{
13 The phenomenological reading contrasts with other popular readings found in the literature, including epistemic, doxastic, comparative, and subjunctive readings. For more, see Alston (2002); Jackson (1977); Chisholm (1957).

${ }^{14}$ Not all theorists agree that phenomenal properties are representational, for example Peacocke (1983) and Block (1990), but in the interest of supporting an IBE argument, I limit attention here to representational theories.
} 
Finally, the libertarian IBE functions in the context of a ceteris paribus clause. If we already have good reason to reject libertarianism, then it is not a candidate for an IBE argument in the first place. For example, non-libertarians raise coherence worries for libertarianism, arguing that the theory cannot provide an adequate account of why a person chose as they did without collapsing into some form of luck. Others argue that libertarianism requires the positing of "spooky entities" that are naturalistically suspect. Libertarians have responded to both objections, though their success is a subject of ongoing debate. Instead of attempting to adjudicate these difficult issues here, I will assume for present purposes that libertarianism can be presented in a plausibly coherent way that is compatible with naturalism in order to investigate the possibility of an IBE for free will. ${ }^{15}$

\section{The Libertarian IBE}

We are now in the position to begin sketching the details of a libertarian IBE. Consider the following argument schema:

1) There are widespread phenomenological appearances of freedom in need of explanation.

2) Libertarianism explains these phenomenological appearances of freedom.

3) There is a range of alternative (both compatibilist and incompatibilist) explanations of appearances of freedom that do not explain the appearances of freedom as well as libertarianism

$\therefore$ We have some reason to think libertarianism is true.

\footnotetext{
${ }^{15}$ For further discussion, see Vargas (2013, Ch. 2)
} 
Considering the wide variety of libertarian and non-libertarian accounts of free will, filling in this schema completely could fill numerous volumes. The aim of this section is merely to sketch the contours of how the libertarian argument might go, and to draw attention to attractive features of the proposed explanation.

Briefly, the libertarian IBE holds that the appearances of freedom are best explained by the fact that we actually are free in the way that it appears. Call this the actualist explanation. The actualist explanation itself relies on the claim that the appearances of freedom are themselves veridical perceptions, which (generally speaking), accurately track how we make choices. Not all forms of libertarianism can support the actualist explanatory strategy, since some forms of libertarianism would predict different appearances of freedom were we to veridically perceive the process by which we make choices. In this section, I argue that the actualist explanation resulting from the conjunction of agent causal libertarianism with an empirically plausible perceptual theory of choice representation is attractive because it (1) explains the largest class of appearances of freedom, (2) with the fewest resources, and (3) is the most conservative, in that it makes the appearances of freedom, and prior beliefs formed on their basis, generally veridical. For these reasons, I argue in section 2.4 , that in the current absence of a better non-libertarian alternative, there is a prima facie case to be made for agent causal libertarianism on the basis of the libertarian IBE.

\subsection{Premise 1}

To fill in the first premise of the Libertarian IBE Schema, we can look back to the list of appearances from section 1. Recall that there is a wide range of appearances of freedom, including the experience of agency, the experience of indeterminism, and the experience of choosing in view of one's reasons, among many others. These are phenomenological claims 
about what it is like to exercise agency. The list is always open to revision, by adding, dropping, or modifying the descriptions of the appearances to be explained. Still, the provided list is compiled from descriptions collected from libertarian and non-libertarian philosophers alike. Other things being equal, the theory that can explain the largest class of these appearances is preferable to those that explain fewer.

\subsection{Premise 2}

The core intuition of the libertarian IBE is that the appearances of freedom can be explained by the fact that we actually are free in the way that it appears. In this sense, libertarianism explains the appearances of freedom in much the same way that the existence of a tree explains my having a visual experience as of a tree in front of me. I have an experience as of a tree in front of me, in part, because there actually is a tree in front of me.

Notice that, in the analogy to visual perception above, the existence of the tree explains the contents of the experience only on the further implicit assumption that I am perceptually related to the tree in the appropriate way. Similarly for the actualist explanation. The existence of libertarian free will explains the appearances of freedom only on the further implicit assumption that we are related to our decision-making processes in an appropriate way. After all, the truth of libertarianism as a metaphysical thesis seems consistent with a possible world in which agents have all the metaphysical capacities required of libertarianism, but enjoy no experiences whatsoever. ${ }^{16}$

Because of the above possibility, the libertarian owes an account of the relationship between the appearances of freedom and the free choices they purport to be about, at least in sketch. Are the appearances of freedom perceptual states, or cognitive states, or conative states?

\footnotetext{
${ }^{16}$ Strawson (1986, Ch. 14).
} 
Are they veridical? Answering these questions requires what we might call a theory of choice representation for the appearances of freedom, in addition to a metaphysics of free choice. As I am using the term here, a "theory of choice representation" provides an account of the particular way in which the appearances of freedom come to phenomenally represent our choices as having certain properties, in much the same way that a "theory of visual perception" explains how visual states come to represent the external world as having various properties. ${ }^{17}$

The above observation considerably complicates the IBE for libertarianism by substantially increasing the number of competing hypotheses. On a phenomenological reading of appearance claims, it is not libertarianism per se that we are assessing for explanatory adequacy. Rather, we are assessing libertarianism (L) combined with some theory of choice representation, $T$. In which case, for the argument to support libertarianism, it must be that $(L+T)$ is a better explanation of the phenomenology than non-libertarianism combined with the same theory of choice representation, $(C+T)$, as well as non-libertarianism combined with any of the alternative theories of choice representation, $\left(C+T^{*}\right)$. Furthermore, it must be that $(L+T)$ provides a better explanation than any theory of choice representation $T^{*}$ taken in isolation. Unless this is so, the IBE will end up providing support for a theory of choice representation, but not necessarily for a theory of free will. For example, it could be the case that choices are made via one process, while appearances of freedom result from a completely different, causally isolated process, or that the appearances of freedom are an artifact of some monitoring process without being representative of objective features in the world. ${ }^{18}$

\footnotetext{
17 I take it to be a virtue of the IBE approach that it is neutral with respect to which theory of consciousness one deploys in a theory of choice representation: higher order thought theories of consciousness, higher order perception theories, reflexive theories, etc. could all be used in an explanation of the way that the appearances of freedom come to represent purported properties of choices.

${ }^{18}$ Admittedly, once the introspective process that gives rise to experiences of freedom is fully specified, one risks rendering the underlying metaphysics explanatorily redundant. That is, because the phenomenal character of appearances of freedom might be largely an artifact of the system by which the experiences are produced, questions
} 
If libertarianism is to provide a better explanation than non-libertarian alternatives, then, it at least needs to be the case that appearances of freedom generally track the properties of our actual decision-making processes in the correct way. For this reason, philosophers who promote actualist explanations of the appearances of freedom have been drawn to perceptual, or quasiperceptual, approaches to the theory of choice representation. ${ }^{19}$

Whether the appearances of freedom are the result of a perceptual or quasi-perceptual process is an empirical question still under investigation. Nevertheless, there is not yet good scientific grounds for ruling out perceptual or quasi-perceptual theories of choice representation. In fact, two of the three major approaches to explaining experiences of first-person agency in the cognitive sciences are consistent with a quasi-perceptual approach, and so consistent with a quasi-perceptual approach to some of the appearances of freedom by extension, though there is still much disagreement in the scientific community. ${ }^{20}$

There are currently three received explanations of experiences of first-person agency: comparator models, multi-factor system models, and apparent mental causation models. Although we do not have space to go into details here, the important point is that the first two models involve quasi-perceptual processes as core components. According to comparator models, experiences of first-person agency arise when forward-looking motor plans match the returning sensory consequences of an action. ${ }^{21}$ Supporters of these models of the experience of first-person agency compare our knowledge of our own acting to visual perception. ${ }^{22}$ Because

\footnotetext{
about phenomenal character may turn out to be orthogonal to the metaphysics of free will. In which case, even if choices $d o$ have the properties libertarians think they have, the veridicality condition would be redundant. This is not to say that veridicality may not be a good-making feature of the explanation; only that veridicality is not a necessary component of an explanation of the appearances of freedom.

${ }^{19}$ See O’Connor (1995, 200); Pink (2004, 122); Mawson (2011); Bayne (2011, 6).

${ }^{20}$ Mylopoulos (2015) argues that agentive awareness cannot result from specialized sense modalities. I take it that this is nevertheless consistent with the appearances of freedom being quasi-perceptual.

${ }^{21}$ Haggard \& Tsakiris (2009); Blakemore, Wolpert, \& Frith (2002); Moore \& Obhi (2012).

22 Prinz (2003); Jeannerod (1997)
} 
these models rely on feedback from the execution of an action, they involve quasi-perceptual components. Multi-factor system models similarly include quasi-perceptual components, but also include additional non-perceptual processing not found in comparator models. ${ }^{23}$ Again, there is still considerable disagreement among cognitive scientists. But given that two of the three plausible candidates are consistent with quasi-perceptual approaches to a theory of choice representation, we have no reason to rule out the actualist explanation on scientific grounds. ${ }^{24}$

With a perceptual approach a theory of choice representation in hand, we can now present the full actualist explanation of the various appearances of freedom outlined in section 2 . The experience of agency provides a simple illustration.

The experience of agency- It appears that I am active with respect to my actions because I actually am active with respect to my actions, and this property of my agency is accurately represented in my (quasi)-perceptual experience of my own agency.

Mutatis mutandis for the other experiences.

\subsection{Premise 3- Assessing Libertarian Alternatives}

Up to this point, I have discussed libertarianism as though it were a single view.

However, there are numerous forms of libertarianism, and it is not obvious that all of them can make equal use of the actualist explanation. As a first pass, all forms of libertarianism are committed to the falsity of determinism. This suggests that all forms of libertarianism can provide actualist explanations for the following appearances of freedom: the experience of a

\footnotetext{
${ }^{23}$ Moore (2016); Moore and Fletcher (2012); Carruthers (2012).

${ }^{24}$ In contrast to the two models mentioned above, the theory of apparent mental causation models largely divorces appearances of freedom from the processes that give rise to action (Wegner, 2002). On apparent mental causation approaches, appearances of freedom arise from ad hoc inferences that do not directly track the processes they purport to be about. The main contention of this view, however, is that experiences of agency are not themselves causes of voluntary actions. This is consistent with the view that experience generally, though fallibly, accurately represents how voluntary actions are brought about.
} 
psychological causal gap, the experience of indeterminism, and the experience of openness. Not all forms of libertarianism, however, are equally well positioned to explain the other appearances of freedom.

Event causal and non-causal versions of libertarianism that lack agents as central components, for example, may have difficulty explaining the agentive aspects of the appearances of freedom. Generally speaking, the experience of agency, the experience of self-as-source, and the experience of exercising a power of control all include the notion of an agent who is active with respect to their actions. It is not at all clear how event causal and non-causal forms of libertarianism that do not include agents as fundamental parts of their theories, such as those defended by Kane (1996) and Ginet (1997), can provide actualist explanations of the agentive aspects of the appearances of freedom.

In contrast, agent causal libertarianism is preferable to event and non-causal theories on IBE grounds in light of these shortcomings. Agent causation just is the active exercise of a power by an agent. ${ }^{25}$ Appearances of freedom like the experiences of agency, self-as-source, and exercising a power of control are experiences of actual powers posited by agent causation. In addition, the agent causal libertarian can adopt the actualist explanations of the other appearances of freedom. Since agent causal libertarianism can provide actualist explanations of the entire range of the appearances of freedom, not just a subset, it is explanatorily preferable, ceteris paribus, to other forms of libertarianism.

The actualist explanation also provides a plausible account for why there are apparently widespread beliefs about the appearances of freedom. Whether or not there is a widespread belief in libertarian freedom, people often seem to believe that they experience their choices in

\footnotetext{
${ }^{25}$ For argument, see O’Connor (1996).
} 
the ways described by the appearances of freedom. Unfortunately, there is as yet little empirical work on beliefs about experiences of freedom, though what little work there is increasingly supports the claim that people think about their experiences of choosing in libertarian terms. ${ }^{26}$ Casual polling suggests that many undergraduates describe their experiences using libertarian terms. ${ }^{27}$ And numerous libertarian, non-libertarian, and agnostic philosophers describe their experiences in ways that broadly accord with the appearances of freedom canvassed here. These strands all point towards the tentative conclusion that people tend to believe that their experiences comport with at least some of the appearances of freedom. The agent causal libertarian can provide an actualist explanation that reinforces these beliefs: people often believe that they experience their choices in the ways described by the appearances of freedom, at least in part, because their choices actually appear to them that way. Thus, actualist explanations can account for widespread beliefs regarding the appearances of freedom, in addition to the appearances of freedom themselves.

In addition to its explanatory breadth, the actualist explanation enjoys other theoretic virtues. The actualist explanation shows a great simplicity and elegance. From only two components, a perceptual approach to choice representation and agent causal libertarianism, the theory accounts for all the appearances of freedom on our list. In this way, the actualist explanation provides a unifying explanation, since it does not require a different mechanism to explain each appearance.

Finally, the agent causal explanation of the appearances of freedom is extremely conservative. Other things being equal, we should prefer theories that are consistent with our prior beliefs and experiences. If agent causal libertarianism is correct, then our experiences are

\footnotetext{
${ }^{26}$ Nahmias et. al. (2004); Deery et. al. (2013, 2015a, 2015b); Knobe (2014)

${ }^{27}$ Holton (2010, 86-87).
} 
largely veridical, and apparently widespread beliefs about those experiences of freedom are largely correct as well. We experience choices the way we would expect, were we libertarian free. All of these considerations taken together provide a prima facie case to prefer an agent causal libertarian theory of free will on IBE grounds.

\subsection{Premise 3-Assessing Non-Libertarian Alternatives}

Libertarian IBE in hand, I turn now to potential non-libertarian responses. I find extant non-libertarian responses to be largely inadequate. One obvious move for the non-libertarian is to point out that their theory of free will is consistent with the appearances of freedom. Unfortunately, merely pointing out that one's theory is consistent with the appearances of freedom does not thereby explain why one undergoes the appearances of freedom. This sort of "explanation" would be bizarre in any other context. It would be akin to the pre-Darwin opponent of Paley arguing that creatures created by random chance are consistent with the appearance of design. Consistent, perhaps, but not very explanatory. There is a burden on the non-libertarian to provide a better and more fine-grained explanation of the appearances of freedom.

Another common response to the libertarian IBE dismisses appearances of freedom as illusions. Call this sort of response the illusionist response. The illusionist fails to seriously take up the challenge pressed by the libertarian IBE. Consider D.J. O'Connor, who asks, "We cannot distinguish by introspecting our states of mind whether the feeling of freedom preceding and accompanying a given action is genuine or illusory. And if that is so, how do we know that any 
given action is a free action?" 28 The illusionist raises the possibility that appearances could be mistaken, and takes this to undermine the libertarian argument from experience.

The illusionist takes a step in the right direction. The possibility of illusion weakens the case for a perceptual approach to choice representation, and so weakens the claim that libertarianism is the best explanation of appearances of freedom. However, the strict illusionist fails to recognize that the libertarian argument from appearances is an $I B E$. As a result, they fail to provide any alternative explanation of the appearances of freedom. In the absence of a more plausible alternative, libertarianism still looks to be the best available option.

Furthermore, it seems to me that the mere possibility of illusion does not seriously undermine the perceptual approach to choice representation. Compare cases of visual perception. It is true that we are sometimes subject to visual illusions, and it is also true that we cannot be certain that we are not subject to an illusion merely on the basis of experience. Nevertheless, it is still generally reasonable to believe that the best explanation of the visual appearance as of a tree in front of me is that there is actually a tree in front of me. The burden remains on the illusionist to provide an alternative explanation of widespread experiences and beliefs about experiences, that is also as elegant and conservative as the actualist explanation.

Leaving the illusionists behind, I turn next to a class of non-libertarian responses I call the Spinozan strategy. ${ }^{29}$ Unlike the illusionist, who provides no alternative account of appearances of freedom, Spinozan strategists attempt to "explain away" appearances of freedom. Once again, we could fill numerous volumes with versions of the Spinozan strategy. For present purposes, I focus on the clearest version of the strategy as defended in the recent work of Shaun Nichols (2015). Nichols argues that we mistakenly believe we are uncaused causes because we

\footnotetext{
${ }^{28}$ O’Connor $(1971,19)$

${ }^{29}$ Spinoza (1677/ 2005); Magill (1997); Nichols (2015)
} 
infer from the lack of an experience of causal necessitation to the conclusion that we are not causally necessitated by anything. We make this mistaken inference because we are subject to an illusion of explanatory depth. Nichols seemingly provides an alternative, non-libertarian explanation of one appearance of freedom.

Although the Spinozan strategy seems to provide an alternative explanation of the appearances of freedom, it ultimately explains a different phenomenon. The Spinozan strategist is primarily interested in explaining why people would believe they are not causally necessitated, but says nothing about why people would experience themselves as not causally necessitated. One of the upshots of our earlier discussion was that the appearances of freedom are phenomenological claims. Since the Spinozan strategy explains the belief that choices are not causally necessitated, but not the phenomenology of choice, it fails to explain the appearances of freedom.

Even if we assume (for the sake of argument) that the Spinozan strategy somehow explains the appearance that choice is not causally necessitated, current versions of the Spinozan strategy would still lack the theoretical virtues enjoyed by the actualist explanation. The Spinozan strategy focuses exclusively on explaining away the belief that choices are not causally necessitated, to the exclusion of all other descriptions of the appearances of freedom. For this reason, the Spinozan strategy lacks the generality enjoyed by libertarian alternatives. Furthermore, the Spinozan strategist would be hard pressed to explain all the appearances of freedom without giving up on the comparative elegance and simplicity enjoyed by the libertarian explanation. The problem is that the Spinozan strategy does not obviously generalize to other appearances of freedom. Although it seems prima facie reasonable to believe we are not causally necessitated on the basis of a lack of an experience of causal necessitation, it is not at all 
clear why we would believe, for example, that we are active with respect to our choices on the basis of that same experience. This suggests that in order to account for other beliefs, the Spinozan strategist will have to provide a different explanation for each belief.

The illusionist accepts libertarian descriptions of the appearances of freedom but dismisses them as illusions. The Spinozan strategist denies select appearances of freedom but tries to explain why we might form beliefs with certain contents. Neither explains the wide range of appearances of freedom as well as the actualist explanation. Nevertheless, a small minority of non-libertarians have attempted to explain some of the appearances of freedom without denying them wholesale. ${ }^{30}$ These theorists provide promising first steps towards addressing the libertarian IBE challenge.

Richard Holton's compatibilist account of experiences of freedom takes a partial firststep towards addressing the libertarian challenge. On Holton's view, choices are caused by unconscious mental processes and mechanisms buried deep in the unconscious. Choices are not, however, causally determined by the beliefs and desires we discover via conscious introspection. When we experience our choices as not causally determined by beliefs and desires, the experiences are veridical. The problem is that we mistakenly infer that our choices are not caused at all on the basis of the experience that our choices are not caused by our beliefs and desires. According to Holton, while our experiences are not illusions, we make inferences beyond the scope of our experiential content, resulting in a collection of false beliefs.

Holton's account regains some of the elegance seen in libertarian explanations. Those mental states to which we do have conscious access are not causal determiners of our choice. Instead, choices are causally determined by unconscious states. Given this view of how choices

\footnotetext{
${ }^{30}$ Holton (2009); Deery (2014)
} 
proceed, one would expect to have the experience that choices are not causally determined by consciously accessible beliefs and desires. And that is precisely what we do in fact experience, according to Holton.

Despite this gain I think Holton's explanation still falls short of the libertarian challenge. Like other non-libertarian accounts, Holton is unable to explain the larger scope of appearances of freedom. Consider the experience of exercising the power of control. Even if my prior consciously considered beliefs and desires are not causal determiners of my choice, it is not clear how this fact could explain why I would experience the power of control. While Holton takes a promising first step, his explanation does not yet match the agent causal libertarian when it comes to breadth of explanation. As a final note on non-libertarian alternatives, if appearances of freedom are taken at face value, then any non-libertarian account will be prima facie less conservative than libertarian alternatives when it comes to beliefs about how we experience our choices. Conservatism is not an overwriting consideration, but a consideration in favor of libertarianism nonetheless.

As a final alternative, some non-libertarians argue that we don't appear free, but that since our belief formation is often theory laden, the appearances of freedom could be "read back" into experiences of choice. ${ }^{31}$ In this sense, appearances of freedom are purely products of inference or judgment about experiences of choice. In doing so, these theorists deny that choices have the appearances of freedom. Philosophers who categorically deny the appearances of freedom face an uphill battle. As I have shown, many non-libertarian philosophers nevertheless agree that many of the appearances of freedom accompany choices. On the experimental side, in many cases, beliefs about experiences seem to be libertarian, but judgments of freedom and

\footnotetext{
${ }^{31}$ Horgan $(2011 a, 2011 b)$
} 
responsibility are a mixed bag of compatibilism and incompatibilism. ${ }^{32}$ If folk theories of free will are not clearly libertarian, it is hard to see why reading those theories back into interpretations of the phenomenology would result in comparatively strong libertarian interpretations of the appearances. Once again, the debate is ongoing, but I think agent causal libertarianism currently has the upper hand.

\section{Conclusion}

I close with advice for non-libertarians. I have argued here that, as it currently stands, agent causal libertarianism provides the best explanation of appearances of freedom, other things being equal. Because IBE is a form of ampliative inference, there is an explanatory burden on the non-libertarian to provide a more plausible alternative. I fear that as it stands, no nonlibertarian has even come close to addressing the burden. As a result, I urge non-libertarians (myself included) to approach the appearances of freedom in a more systematic and honest fashion. The first step in addressing this burden involves recognizing libertarian appeals to the appearances of freedom as genuine arguments, and not the pig-headed dogmatism sometimes ascribed to it. Hopefully, I have made some progress here in clarifying the argument and identifying the burden: to provide an explanation of the wide breadth of appearances of freedom that is comparable to libertarian alternatives with respect to other desirable theoretical virtues.

\section{Works Cited}

${ }^{32}$ Feltz (2017) 
Alston, W. P. (2002). Sellars and the "myth of the given." Philosophy and Phenomenological Research, 65(1), 69-86.

Bayne, T. (2011). The Sense of Agency. In F. MacPherson (Ed.), The Senses: Classic and Contemporary Philosophical Lessons. Oxford University Press.

Blakemore, S. J., Wolpert, D. M., \& Frith, C. D. (2002). Abnormalities in the awareness of action. Trends in Cognitive Sciences, 6(6), 237-242.

Boyle, J. M., Grisez, G., \& Tollefson, O. (1976). Free Choice: A Self Referential Argument. Notre Dame, Ind.: University Press of Notre Dame.

Campbell, C. A. (1967). In Defence Of Free Will, With Other Philosophical Essays. London,: Allen \&Amp; Unwin.

Carruthers, G. (2012). The case for the comparator model as an explanation of the sense of agency and its breakdowns. Consciousness and Cognition, 21(1), 30-45.

Chisholm, R. (1957). Perceiving: A Philosophical Study. Ithaca, New York: Cornell University Press.

Deery, O. (2015a). Is agentive experience compatible with determinism? Philosophical Explorations, 18(1), 2-19.

Deery, O. (2015b). Why people believe in indeterminist free will. Philosophical Studies, 172(8), 2033-2054.

Deery, O. (2014). The Fall From Eden: Why Libertarianism Isn’t Justified By Experience. Australasian Journal of Philosophy, 93(2), 319-334.

Deery, O., Bedke, M. S., \& Nichols, S. (2013). Phenomenal Abilities: Incompatibilism and the Experience of Agency. In D. Shoemaker (Ed.), Oxford Studies in Agency and Responsibility (pp. 126-150). Oxford University Press.

Descartes, R. (1641/1984). The Philosophical Writings of Descartes. (J. Cottingham, R. Stoothoff, \& D. Murdoch, Eds.). Cambridge: Cambridge University Press.

Doris, J. M. (2015). Talking to our selves : reflection, ignorance, and agency. Oxford University Press.

Feltz, A. (2017). Folk Intuitions. In K. Timpe, M. Griffith, \& N. Levy (Eds.), The Routledge Companion to Free Will (pp. 468-476). New York: Routledge.

Haggard, P., \& Tsakiris, M. (2009). The Experience of Agency: Feelings, Judgments, and Responsibility. Current Directions in Psychological Science, 18(4), 242-246. 
Hobbes, T. (2005). The questions concerning liberty, necessity, and chance clearly stated and debated between Dr. Bramhall, Bishop of Derry, and Thomas Hobbes of Malmesbury. Retrieved from http://name.umdl.umich.edu/A44010.0001.001

Holton, R. (2010). Disentangling the Will. In R. Baumeister, A. Mele, \& K. Vohs (Eds.), Free Will and Consciousness. Oxford: Oxford University Press.

Holton, R. (2009). Willing, Wanting, Waiting. Oxford University Press.

Horgan, T. E., Tienson, J. L., \& Graham, G. (2003). The Phenomenology of First-Person Agency. In S. Walter \& HeckmannHeinz-Dieter (Eds.), Physicalism and Mental Causation (p. 323). Imprint Academic.

Horgan, T. (2011a). The Phenomenology of Agency and Freedom : Lessons from Introspection and Lessons from Its Limits. Humana Mente, (15), 77-97.

Horgan, T. (2011b). Causal compatibilism about agentive phenomenology. In T. Horgan, M. Sabates, \& D. Sosa (Eds.), Supervenience in Mind. Cambridge, MA: MIT Press.

Huemer, Michael. 2007. "Compassionate Phenomenal Conservatism.” Philosophy and Phenomenological Research 74, 30-55.

Hume, D. (1748/2011). An Enquiry Concerning Human Understanding,. (E. Steinberg, Ed.) (2nd ed.). Hackett Publishing Co.

Hume, D. (1779/2007). Dialogues Concerning Natural Religion and Other Writings. Cambridge Univ. Press.

Jackson, F. (1977). Perception: A Representative Theory. Cambridge University Press.

James, W. (1902). The Varieties of Religious Experience: A Study in Human Nature. Dover Publications.

Kapitan, T. (1986). Deliberation and the presumption of open alternatives. The Philosophical Quarterly, 36(14), 230-251.

Kissel, A. (2018). Indeterministic Intuitions and the Spinozan Strategy. Mind \& Language, 2018.

Knobe, J. (2014). Free Will and the Scientific Vision. In E. Machery \& E. O’Neill (Eds.), Current Controversies in Experimental Philosophy (pp. 69-85). Routledge.

Kraut, R. (2001). Metaphysical Explanation and the Philosophy of Mathematics: Reflections on Jerrold Katz's Realistic Rationalism. Philosophia Mathematica, 9(2), 154-183.

Lewis, D. K. (1973). Counterfactuals. Blackwell Publishers. 
Lipton, P. (2004). Inference to the Best Explanation. Routledge/Taylor and Francis Group.

Lycan, W. G. (2002). Explanation and Epistemology. In P. K. Moser (Ed.), Oxford Handbook of Epistemology (pp. 408-433). New York: Oxford University Press.

Magill, K. (1997). Freedom and experience: self-determination without illusions. New York: St. Martin's Press.

Maund, J. B. (1986). The Phenomenal and Other Uses of "Looks." Australasian Journal of Philosophy, 64(2), 170-180.

Mawson, T. J. (2011). Free Will: A Guide for the Perplexed. Bloomsbury Academic.

Moore, J. W. (2016). What is the sense of agency and why does it matter? Frontiers in Psychology, 7(AUG), 1-9.

Moore, J. W., \& Fletcher, P. C. (2012). Sense of agency in health and disease: A review of cue integration approaches. Consciousness and Cognition, 21(1), 59-68.

Moore, J. W., \& Obhi, S. S. (2012). Intentional binding and the sense of agency: A review. Consciousness and Cognition, 21(1), 546-561.

Mylopoulos, M. I. (2014). Agentive awareness is not sensory awareness. Philosophical Studies, 172(3), 761-780.

Nahmias, E., Morris, S. G., Nadelhoffer, T., \& Turner, J. (2004). The Phenomenology of Free Will. Journal of Consciousness Studies, 11(7-8), 162-179.

Nichols, S. (2015). Bound: Essays on Free Will and Responsibility. Oxford University Press.

Nichols, S., \& Knobe, J. (2007). Moral Responsibility and Determinism: The Cognitive Science of Folk Intuitions. Nô̂s, 41(4), 663-685.

O’Connor, T. (1995). Agent Causation. In Agents, Causes, and Events: Essays on Indeterminism and Free Will (pp. 173-200). New York: Oxford University Press.

Open Science Collaboration. (2015). Estimating the reproducibility of psychological science. Science, 349(6251).

Pink, T. (2004). Free will a very short introduction. Oxford; New York: Oxford University Press.

Pink, T. (2010). Free Will and Consciousness. In T. Bayne, A. Cleeremans, \& P. Wilken (Eds.), The Oxford Companion to Consciousness. Oxford University Press. 
Prinz, W. (2003). How do we know about our own actions? In S. Maasen, W. Prinz, \& G. Roth (Eds.), Voluntary Action: Brains, minds, and sociality (pp. 21-33). Oxford Univ. Press.

Rozenblit, L., \& Keil, F. The misunderstood limits of folk science: an illusion of explanatory depth. Cognitive Science, 92(2002), 1-42.

Sarkissian, H., Chatterjee, A., De Brigard, F., Knobe, J., Nichols, S., \& Sirker, S. (2010). Is Belief in Free Will a Cultural Universal? Mind \& Language, 25(3), 346-358.

Searle, J. R. (2003). Rationality in action. Cambridge, Mass.; London: MIT.

Searle, J. R. (2007). Freedom and Neurobiology: Reflections on Free Will, Language, and Political Power. Columbia University Press.

Smilansky, S. (2005). Free will and illusion. Clarendon Press.

Sommers, T. (2007). The Illusion of Freedom Evolves. In D. Ross, D. Spurrett, H. Kincaid, \& G. L. Stephens (Eds.), Distributed Cognition and the Will: Individual Volition in Social Context (pp. 61-75). MIT Press.

Spinoza, B. de, \& Hampshire, S. (1677/2005). Ethics. (E. Curley, Trans.). Penguin Classics.

Strawson, G. (1986). Freedom and Belief. Oxford: Clarendon press.

Swinburne, R. (2013). Mind, brain, and free will. Oxford: Oxford Univ. Press.

van Fraassen, B. C. (1980). The Scientific Image. Clarendon Press.

Vargas, M. (2013). Building Better Beings: A Theory of Moral Responsibility. Oxford Univ. Press.

Williamson, T. (2004). Philosophical "Intuitions" and Scepticism about Judgement. Dialectica, 58(1), 109-153. 